\title{
Salivary Nitrate, Nitrite and Nitrate Reductase Activity in Relation to Risk of Oral Cancer in Egypt
}

\author{
Alaa F. Badawi ${ }^{1, \#}$, Gehan Hosny ${ }^{2}$, Mohamed \\ El-Hadary ${ }^{3}$ and Mostafa H. Mostafa ${ }^{2}$ \\ ${ }^{1}$ Laboratory of Pharmacogenetics, University \\ of Prince Edward Island, Canada \\ ${ }^{2}$ Department of Environmental Studies, \\ University of Alexandria, Egypt \\ ${ }^{3}$ Department of Operative Dentistry, \\ University of Alexandria, Egypt
}

\begin{abstract}
It has been suggested that nitrate and nitrite may play a role in the etiology of human oral cancer. We investigated whether salivary nitrate and nitrite and the activity of nitrate reductase (NRase) may affect the risk of oral cancer in Egypt, an area with high levels of environmental nitrosating agents. Levels of salivary nitrite $(8.3 \pm 1.0 \mu \mathrm{g} / \mathrm{ml})$ and nitrate $(44 \pm 3.7 \mu \mathrm{g} / \mathrm{ml})$ and activity of NRase $(74 \pm 10$ $\mathrm{nmol} / \mathrm{ml} / \mathrm{min})$ were significantly $(P<0.05)$ higher in oral cancer patients $(n=42)$ compared to control Egyptian healthy individuals $(n=40, \quad$ nitrite $=$ $5.3 \pm 0.3 \mu \mathrm{g} / \mathrm{ml}$, nitrate $=27 \pm 1.2 \mu \mathrm{g} / \mathrm{ml}$, and NRase activity $=46 \pm 4 \mathrm{nmol} / \mathrm{ml} / \mathrm{min}$ ). The adjusted odds ratio (OR) and the $95 \%$ confidence intervals (C.I.) for risk of oral cancer, categorized by the levels of salivary nitrate and nitrite and NRase activity, showed a higher cancer risk associated with nitrite $>7.5 \mu \mathrm{g} / \mathrm{ml}$ (OR: 3.0, C.I.: 1.0-9.3), nitrite $>40 \mu \mathrm{g} / \mathrm{ml}$ (OR: 4.3, C.I.: $1.4-13.3)$ and NRase activity $>50 \mathrm{nmol} / \mathrm{ml} / \mathrm{min}$ (OR: 2.9, C.I.: 1.1-7.4). Our findings suggest that increased consumption of dietary nitrate and nitrite is associated with elevated levels of salivary nitrite. Together with the increased activity of salivary NRase, these observations may explain, at least in part, the role of nitrate and nitrite in the development of oral cancer in individuals from an area with a high burden of $N$-nitroso precursors.
\end{abstract}

\footnotetext{
\# Correspondence: Laboratory of Pharmacogenetics, University of Prince Edward Island, 550 University Av., Charlottetown, PE, Canada C1A 4P3, Tel: +1 9025660894 , Fax: +1 902566 0832, email: abadawi@upei.ca
}

\author{
ABBREVIATIONS: C.I.: confidence intervals, \\ Nrase: nitrate reductase, NOC: $N$-nitroso compounds, \\ OR: odds ratio
}

KEYWORDS: Nitrate, nitrite, nitrate reductase, oral cancer, saliva

\section{INTRODUCTION}

High levels of dietary nitrate have long been considered risk factors in the development of various types of cancer in humans [12]. Nitrate can be reduced to nitrite in the oral cavity and then react with amines and amides to form $\mathrm{N}$ nitroso compounds (NOC) [4]. NOC and other alkylating agents are carcinogenic to multiple organs in at least 40 animal species including higher primates [6] and may also have a similar effect in humans [20]. Nitrate is highly concentrated in humans by the salivary glands and secreted into the saliva at levels that may reach 10 -fold higher than plasma concentrations [28]. Saliva contains little or no nitrite when secreted, but nitrate is rapidly reduced to nitrite after exposure to the oral cavity. This reduction occurs mainly on the posterior surface of the tongue [9] in a reaction catalyzed by the nitrate reductase (NRase) enzyme. NRase is present in mammalian cells and can also be synthesized in many anaerobic, mouth colonizing, nitratereducing micro-organisms when exposed to low oxygen tension [9].

Measures of susceptibility and risk factors of oral cancer have yet to be identified in order to evaluate the genetic and biological markers of the disease. The analysis of salivary and dietary nitrate and nitrite has been used as a measure of exogenous nitrate burden [28] as well as an indicator of risk for upper aerodigestive tract cancers [22]. Indeed, a link between oral cancer 
and increased consumption of nitrite- and NOCcontaining food has been suggested [24]. In Egypt, the levels of environmental nitrate and nitrite [17], the daily nitrate intake per person [1], the concentrations of salivary nitrate and nitrite $[21,30]$, and the levels of dietary NOC [10] were all estimated to be higher than the levels observed in many Western countries [1,2]. However, these studies focused mainly on the relevance of nitrate/nitrite in bladder cancer development, but not oral cancer.

Cancer of the oral cavity represents a significant problem in Egypt due to its high incidence, poor survival rate, and the severe functional and cosmetic defects accompanying the treatment [15]. Therefore, in order to achieve practical means of prevention, an idealized quantitative approach should be developed to provide precarcinogenic biomarkers capable of predicting those individuals at high risk of oral cancer.

The present study, therefore, reports the levels of salivary nitrate and nitrite and the activity of NRase in oral cancer patients from Egypt in order to evaluate the role of these factors in the etiology of the disease. Moreover, these studies may allow consideration of ways by which early detection and possible prevention might be achieved.

\section{MATERIALS AND METHODS}

Cases diagnosed for cancer of the oral cavity (n: 42 ; average age: $44 \pm 14 \mathrm{yrs}$ ) were recruited over a period of six months, to minimize seasonal changes in food consumption, from the Department of Maxillo-facial Surgery, and the Department of Oncology and Nuclear Medicine, University of Alexandria where they were histologically confirmed for the tumor type (Table 1). Concurrently, control subjects (n: 40; average age $50 \pm 16$ yrs.) without any current or prior diagnosis of cancer or present respiratory diseases were selected from members of the academic staff and students at the Institute of Graduate Studies and Research, Alexandria. Controls showed both hygienic $(n=29)$ and non- hygienic $(\mathrm{n}=11)$ conditions. The latter conditions were present only as minor signs of inflammation (Table 1). Demographic information was collected for all cases and controls by administering a short questionnaire that included age, tobacco use, and certain dietary habits (frequency of meat, tea, and fruit consumption per week). Details on the number of subjects (cases versus controls) in each group and category are shown in Table 2. Data on alcohol consumption were unobtainable as most of the subjects claimed to be non-users due to religious and legal restrictions on alcohol use in Egypt.

Saliva samples (mid-morning and afternoon) were collected from the study subjects in two separate portions: a) the first served for the analysis of nitrate and nitrite and was collected in plastic vials containing a glass frit impregnated with $10 \mathrm{M}$ sodium hydroxide for stabilization and to prevent bacterial growth and/or bacterial reduction of nitrate to nitrite; $b$ ) the second was collected in plastic vials, immediately frozen in liquid $\mathrm{N}_{2}$ and stored at $-80{ }^{\circ} \mathrm{C}$ for the analysis of NRase activity.

Table 1

Frequency of pathological characteristics in the study subjects

\begin{tabular}{lc}
\hline \multicolumn{1}{c}{ Pathology } & Frequency (\%) \\
\hline Cases: & 19 \\
SCC of the toung ${ }^{\mathrm{a}}$ & 10 \\
SCC of the right maxilla & 10 \\
Salivary gland carcinoma & 10 \\
Right maxillary tumor & 7 \\
Mandible cancer & 7 \\
SCC of the oropharynx & 7 \\
SCC of the retromolar area & 7 \\
Supraglotic carcinoma & \\
Pleomorphic adenoma of & 7 \\
minor salivary glands & 5 \\
Cancer of the mouth floor & 5 \\
Lip cancer & 2 \\
Mucoepidermoid carcinoma & 2 \\
SCC of the alveolar margin & 2 \\
Tonsillar tumor & \\
& \\
Controls: & \\
Non-hygienic (minor signs of & 28 \\
inflammation) & 72 \\
Hygienic &
\end{tabular}


Table 2

Salivary levels of nitrite and nitrate and nitrate-reductase activity in the study subjects categorized by gender, age, smoking status, and dietary factors ${ }^{\mathrm{a}}$

\begin{tabular}{|c|c|c|c|c|c|c|c|}
\hline \multirow{2}{*}{ Variable } & \multirow{2}{*}{$\begin{array}{c}\text { Number (n) } \\
\text { Cases/Controls }\end{array}$} & \multicolumn{2}{|c|}{ Nitrite $(\mu \mathrm{g} / \mathrm{ml})$} & \multicolumn{2}{|c|}{ Nitrate $(\mu \mathrm{g} / \mathrm{ml})$} & \multicolumn{2}{|c|}{ NRase $(\mathrm{nmol} / \mathrm{ml} / \mathrm{min})$} \\
\hline & & Cases & Controls & Cases & Controls & Cases & Controls \\
\hline All subjects & $42 / 40$ & $8.3 \pm 1.0^{\mathrm{b}}$ & $5.3 \pm 0.3$ & $44 \pm 3.7^{b}$ & $27 \pm 1.2$ & $74 \pm 10^{\mathrm{b}}$ & $46 \pm 4$ \\
\hline \multicolumn{8}{|l|}{ Gender } \\
\hline M & $20 / 23$ & $9.4 \pm 1.8$ & $4.9 \pm 0.4$ & $42 \pm 4.7$ & $27 \pm 1.5$ & $88 \pm 15$ & $48 \pm 5$ \\
\hline F & $22 / 17$ & $7.0 \pm 0.7$ & $5.9 \pm 0.4$ & $47 \pm 4.8$ & $26 \pm 2.1$ & $58 \pm 14$ & $44 \pm 6$ \\
\hline \multicolumn{8}{|l|}{ Age } \\
\hline$<30$ & $5 / 10$ & $6.3 \pm 1.3$ & $4.4 \pm 0.5$ & $35 \pm 4.6$ & $28 \pm 1.9$ & $105 \pm 33^{\mathrm{c}}$ & $49 \pm 7$ \\
\hline $30-40$ & $8 / 9$ & $9.7 \pm 3.2$ & $5.4 \pm 0.5$ & $55 \pm 10.9$ & $29 \pm 3.3$ & $120 \pm 36$ & $40 \pm 9$ \\
\hline $41-50$ & $9 / 10$ & $11.5 \pm 3.2$ & $5.6 \pm 0.7$ & $51 \pm 7.9$ & $26 \pm 1.6$ & $78 \pm 22$ & $48 \pm 7$ \\
\hline $51-60$ & $7 / 17$ & $5.8 \pm 1.0$ & $6.3 \pm 0.6$ & $33 \pm 3.7$ & $24 \pm 3.5$ & $40 \pm 9^{d}$ & $32 \pm 6$ \\
\hline$>60$ & $12 / 4$ & $7.2 \pm 1.1$ & $5.8 \pm 1.0$ & $42 \pm 5.5$ & $23 \pm 3.3$ & $49 \pm 7^{\mathrm{d}}$ & $66 \pm 5$ \\
\hline \multicolumn{8}{|l|}{ Smoking } \\
\hline none/ex & $23 / 24$ & $7.0 \pm 0.6^{c}$ & $5.7 \pm 0.4$ & $45 \pm 4.3$ & $26 \pm 1.5$ & $63 \pm 13^{\mathrm{c}}$ & $47 \pm 5$ \\
\hline$<1 \mathrm{pack} /$ day & $16 / 13$ & $8.9 \pm 1.8$ & $4.8 \pm 0.4$ & $41 \pm 5.4$ & $28 \pm 1.6$ & $83 \pm 17$ & $43 \pm 6$ \\
\hline$>1 \mathrm{pack} / \mathrm{day}$ & $3 / 3$ & $14.3 \pm 10^{\mathrm{d}}$ & $5.2 \pm 1.5$ & $55 \pm 20$ & $27 \pm 9.1$ & $108 \pm 50$ & $54 \pm 14$ \\
\hline All Smokers & $19 / 16$ & $10.6 \pm 1.8^{\mathrm{d}}$ & $4.8 \pm 0.4$ & $45 \pm 5.4$ & $28 \pm 1.9$ & $99 \pm 11^{\mathrm{d}}$ & $45 \pm 6$ \\
\hline \multicolumn{8}{|l|}{ Diet } \\
\hline \multicolumn{8}{|l|}{ Meat } \\
\hline$<1 /$ wk & $15 / 18$ & $6.6 \pm 0.9$ & $6.0 \pm 0.4$ & $41 \pm 3.8$ & $26 \pm 1.7$ & $50 \pm 10^{c}$ & $47 \pm 5$ \\
\hline$>1 /$ wk & $27 / 22$ & $9.2 \pm 1.4$ & $4.8 \pm 0.3$ & $46 \pm 4.8$ & $28 \pm 1.6$ & $87 \pm 12^{\mathrm{d}}$ & $45 \pm 7$ \\
\hline \multicolumn{8}{|l|}{ Tea } \\
\hline$<3$ cup/day & $29 / 27$ & $9.1 \pm 1.5$ & $5.5 \pm 0.6$ & $47 \pm 4.1$ & $28 \pm 1.5$ & $78 \pm 12$ & $52 \pm 4$ \\
\hline$>3$ cup/day & $13 / 13$ & $6.7 \pm 0.6$ & $5.0 \pm 0.5$ & $40 \pm 5.9$ & $24 \pm 1.6$ & $66 \pm 20$ & $34 \pm 6$ \\
\hline \multicolumn{8}{|l|}{ Fruit } \\
\hline$<1 /$ wk & $31 / 23$ & $7.9 \pm 1.0$ & $5.6 \pm 0.4$ & $46 \pm 4.3$ & $25 \pm 1.4$ & $72 \pm 12$ & $49 \pm 7$ \\
\hline$>1 / \mathrm{wk}$ & $11 / 17$ & $9.4 \pm 2.8$ & $5.1 \pm 0.4$ & $41 \pm 6.1$ & $29 \pm 2.1$ & $97 \pm 21$ & $43 \pm 6$ \\
\hline
\end{tabular}

${ }^{a}$ Values represent mean \pm S.E.M. of $n$ subjects.

'Denotes a statistically significant difference $(P<0.05)$ from the corresponding control group, using the Student's $t$ test.

${ }^{\mathrm{c}}$ Reference category.

${ }^{\mathrm{d} D}$ Denotes a statistically significant difference $(P<0.05)$ from the corresponding reference category, using the Student's $t$ test.

Nitrate and nitrite concentrations in the saliva samples were determined as previously described [21]. Nitrate reductase activity was measured spectrophotometrically following the oxidation of reduced benzyl viologen, coupled to the reduction of nitrate to nitrite [16].

Statistical analyses for the risk of oral cancer in relation to salivary levels of nitrate and nitrite and the activity of NRase were calculated using odds ratio (OR) and 95\% confidence intervals (C.I.) adjusted for gender, age, smoking status and dietary factors in logistic regression models using SPSS 6.1 statistical package (SPSS Inc.,
Chicago, IL). For comparisons between cases versus controls, Student's $t$ test was used.

\section{RESULTS}

The average levels of nitrate and nitrite and the NRase activity, categorized by gender, age, smoking status and some dietary factors, associated with nitrate/nitrite consumption and risk of oral cancer, are shown in Table 2. Significantly higher levels of nitrite and nitrate and NRase activity were observed in the cases at 
diagnosis vs. controls. No differences were obtained in the three measures between genders or between categories for tea or fruit consumption. Nitrite concentrations were significantly higher in smokers vs. non-smokers and were accompanied by elevated NRase activity. NRase activity was significantly lower in older patients. Meat, but not tea or fruit, consumption was associated with significant elevation in the NRase activity. Oral hygienic conditions in control subjects did not affect the levels of nitrite, nitrate or NRase activity (data not shown).

The odds ratio, adjusted for confounding factors, and the $95 \%$ C.I. for risk of oral cancer categorized by the levels of salivary nitrate and nitrite and NRase activity are shown in Table 3. Levels of the three measures that were found in the control group were used as a reference category. Increased levels of salivary nitrite and nitrite and higher NRase enzyme activity were associated with elevated risk of oral cancer.

\section{DISCUSSION}

Increased nitrate and nitrite burden is linked to higher incidences of several types of malignancies in human populations such as upper aerodigestive tract [24], oral $[13,19]$, stomach [14], and bladder cancers [1,2]. In the present study we measured the levels of nitrate and nitrite and the activity of NRase in the saliva of oral cancer patients and normal individuals in order to evaluate the involvement of these factors in the etiology of oral cancer. We observed significantly elevated levels of nitrate and nitrite and higher NRase activity in cancer patients compared to controls (Table 2). Differences in nitrate concentrations between the two groups may be due to differences in nitrate consumption. However, variations in nitrite levels may be due to differences in both nitrate consumption and the less hygienic conditions associated with oral cancer. Increased intake of nitrate usually causes elevation in the salivary nitrate and nitrite [12] and enhanced risk of oral cancer [13,19]. The main risk factor in susceptible populations is not nitrate per se but its conversion to nitrite and the subsequent formation of the carcinogenic NOC [26]. The oral cavity is a known site of this endogenous nitrosation reaction [23]. Nitrate reduction, mediated by NRase [35] that presents in the saliva from the mouth colonizing bacteria [9] and yeast [18], produces the highest effective nitrite concentration in the human body [28]. Nitrite then reacts with the salivary nitrosatable secondary amines [31] to form the carcinogenic NOC [35] that can play an important role in oral cancer development in humans [29].

In the general Egyptian population, it was estimated that the approximate daily nitrate burden is in excess of $200 \mathrm{mg} /$ day which is 2-fold higher than that in European populations $[1,30]$. Since levels of salivary nitrate in these reports from Egypt $[1,30]$ were comparable to the values reported in the control group from the present study (Table 2), and since cancer patients had $\sim 1.5$-fold higher levels of nitrate compared to healthy controls, it can be suggested that oral cancer patients may have had a relatively higher dietary nitrate intake averaging $\sim 350 \mathrm{mg}$ nitrate/person/day. These elevated levels of nitrate in cancer patients provide a readily available source of nitrate as a substrate for NRase activity as shown by the higher salivary nitrite content (Table 2). Cancer patients,

Table 3

Odds ratio and $95 \%$ confidence intervals for risk of oral cancer by the levels nitrite and nitrate and activity of nitrate-reductase in saliva

\begin{tabular}{lcc}
\hline \multicolumn{1}{c}{ Parameter } & $\mathrm{OR}^{\mathbf{a}}$ & $95 \%$ C.I. \\
\hline Nitrite $(\mu \mathrm{g} / \mathrm{ml})$ & & \\
$\quad<5.0$ & 1.0 & \\
$\quad 5.1-7.5$ & 1.8 & $0.7-5.4$ \\
$\quad>7.5$ & $3.0^{\mathbf{b}}$ & $1.0-9.3$ \\
& & \\
Nitrate $(\mu \mathrm{g} / \mathrm{ml})$ & & \\
$\quad<25$ & 1.0 & $1.1-9.8$ \\
$\quad 25-40$ & $3.3^{\mathbf{b}}$ & $1.4-13.3$ \\
$\quad>40$ & $4.3^{\mathbf{b}}$ & \\
& & \\
NRase $(\mathrm{nmol} / \mathrm{ml} / \mathrm{min})$ & & \\
$\quad<50$ & 1.0 & $1.1-7.4$ \\
$\quad>50$ & $2.9^{\mathbf{b}}$ & \\
\hline
\end{tabular}

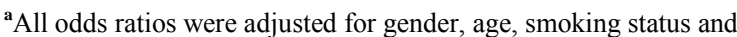
dietary factors.

${ }^{\mathbf{b}} P<0.05$ vs. reference category. 
therefore, will have an enhanced potential of endogenous formation of NOC in the oral cavity that may be a causative factor in cancer development. Indeed, we found a significant association between increased salivary nitrate and nitrite and higher risk of oral cancer (Table 3 ). Moreover, the endogenous formation of these carcinogenic NOC together with the consumption of food containing these agents were epidemiologically linked to increased risk of oral cancer [24].

The high levels of salivary nitrate and nitrite and its association with elevated risk of oral cancer (Table 3 ) are perhaps due partially to the increased NRase activity. NRase activity $>50$ $\mathrm{nmol} / \mathrm{ml} / \mathrm{min}$ was associated with 2.9-fold increased risk of oral cancer (Table 3). Salivary NRase is of a microbial origin, e.g. bacteria or yeast (see above), and mediates the formation of nitrite from salivary nitrate $[9,35]$. Indeed, the number of mouth colonizing micro-organisms, the in vivo oral nitrate reduction, and the salivary nitrate and nitrite concentrations were all correlated with NOC formation [25]. This suggests that individual difference in oral nitrate reduction is a contributory factor in oral cancer development. It should, however, be stated that bacterial and yeast strains with high NRase activity and enhanced nitrosation potential were generally isolated from lesions with more advanced preneoplastic changes in the oral cavity [18]. Therefore, the increase in NRase activity might be due to the less hygienic conditions and the oral cavity infection presents as a result of the oral cancer.

In accordance with earlier investigations, we did not obtain any association between gender [32] or age [33] and the levels of nitrate and nitrite. NRase activity, however, correlated with age (decreased in $>50$ year-old- vs. $<30$ yearold-patients) but not with gender. To our knowledge the present study is the first to examine the effect of age on human salivary NRase activity. The kinetics of the enzyme from other body compartments in animal models suggest a decrease in the activity with age [7].

A significant increase in the NRase activity, and consequently the salivary nitrite was observed in smokers vs. non-smokers (Table 2). This up-regulation in the enzyme activity could be due to the increased levels of the nitrosation catalyst, thiocyanate [11] in the saliva of smokers. Habitual use of various tobacco products was associated with increased levels of nitrite and higher NRase activity in the saliva of users compared to non-users and was also associated with elevated risk of oral cancer [22].

Several studies have shown that dietary factors associated with nitrate/nitrite intake significantly influence the development of oral cancer in human populations $[13,19,24]$. There were no changes in the levels of salivary nitrate or nitrite with meat, tea, or fruit consumption (Table 2). However, a significant elevation in NRase activity was associated with meat intake probably due to the high nitrate content of cured meat [24]. It is interesting to note that NRase activity was highest in the younger groups of patients, and also higher with higher meat consumption. These age-related differences are perhaps attributable to the tendency of the young age groups in Egypt to consume higher amounts of meat compared to older age groups which was evident in the present series of samples (data not shown). It is generally known that increased consumption of red or cured meat is associated with high salivary nitrate [27] and elevated risk of oral cancer [13]. In contrast, fruit intake reduces the risk of oral cancer in epidemiological studies $[13,19]$. Indeed, in the present study we observed a decreased risk of oral cancer with increased fruit intake (using Yates' Continuity Corrected $\chi^{2}$-test: crude OR, $0.35 ; 95 \%$ C.I., $0.13-0.89 ; P<0.05$; data not shown). Such a protective effect is due to the presence of inhibitors of nitrosation reaction in fresh fruit, e.g. vitamins $\mathrm{C}$ and $\mathrm{E}$ and phenolic compounds [5]. This suggestion should be a subject of further investigation in a larger sample size in order to define the mechanism by which fruits protect against oral cancer. However, the consensus of available information strongly implicates an association between fruit consumption and lower risk of oral cancer $[8,13,19]$. This observation can provide a measure that should be implemented in an 
effective strategy for oral cancer prevention in Egypt. A possible protective effect of tea consumption on oral cancer was also suggested since tea contains polyphenols, e.g. flavonoids, which have antioxidant properties [34]. This protective effect of tea was not evident in the present study, in agreement with other epidemiologic reports $[13,19]$.

In conclusion, the results of the present study demonstrate that increased levels of salivary nitrate and nitrite and high NRase activity can be associated with elevated risk of oral cancer in Egypt, an environment with a high burden of $\mathrm{N}$ nitroso precursors. By incorporating these biological markers into human biomonitoring studies, environmental hazards might be detected early enough in the process of oral cancer development to identify those individuals at potentially elevated risk [3]. Moreover, such markers could assist in the extrapolation of cancer risk from one human population to another.

\section{Acknowledgments}

We thank Dr. A. El-Sohemy, Department of Nutritional Sciences, Faculty of Medicine, University of Toronto, Canada, for valuable suggestions.

\section{References}

[1] Badawi, A.F., Mostafa, M.H. and O'Connor, P.J. Involvement of alkylating agents in schistosomeassociated bladder cancer: the possible basic mechanisms of induction. Cancer Lett. 63, (1992) 171-188.

[2] Badawi, A.F., Mostafa, M.H., Probert, A. and O'Connor, P.J. Role of schistosomiasis in human bladder cancer: evidence of association, etiological factors and basic mechanisms of carcinogenesis. Eur. J. Cancer Prev. 4, (1995) 45-59.

[3] Badawi, A.F., Stern, S.J., Lang, N.P. and Kadlubar, F.F. Cytochrome P450 and acetyltransferase expression as biomarkers of carcinogen-DNA adduct levels and human cancer susceptibility. Prog. Clin. Biol. Res. 395, (1996) 109-140.

[4] Bartsch, H. N-nitroso compounds and human cancer: where do we stand? IARC. Sci. Publ. 105, (1991) 1-10.

[5] Bartsch, H., Ohshima, H. and Pignatelli, B. Inhibitors of endogenous nitrosation. Mechanisms and implications in human cancer prevention. Mut. Res. 202, (1988) 307-324.

[6] Bogovski, P. and Bogovski, S. Animal species in which $\mathrm{N}$-nitroso compounds induce cancer. Int. J. Cancer 27, (1981) 471-474.

[7] Brennan-Craddock, W.E., Mallett, A.K., Rowland, I.R. and Neale, S. Development changes to gut microflora metabolism in mice. $J$. Appl. Bacteriol. 73, (1992) 163-167.

[8] Chang-Clude, J., Waherndorf, J., Qiu, S.L., Yang, G.R., Munoz, N., Crespi, M., Raedsch, R., Thurnham, D.I. and Correa, P. Epidemiological study of precursor lesions of oesophageal cancer among young persons in Huixian, China. IARC Sci. Publ. 105, (1991) 192-196.

[9] Duncan, C., Dougall, H., Johnston, P., Green, S., Brogan, R., Leifert, C., Smith, L., Golden, M. and Benjamin, N. Chemical generation of nitric oxide in the mouth from the enterosalivary circulation of dietary nitrate. Nature Med. 1, (1995) 546-551.

[10] El-Aasar, A.A., El-Merzabani, M.M. and Zakhary, N.I. A study on the aetiological factors of bilharzial cancer in Egypt: 2. Nitrosamines and their precursors in Egyptian dairy products. Eur. J. Cancer 15, (1979) 293-298.

[11] Fan, T.Y. and Tannenbaum, S.R. Factors influencing the rate of formation of nitrosomorphline from morpholine and nitrite: acceleration by thiocynate and other anions. $J$. Agric. Food. Chem. 21, (1973) 237-240.

[12] Fraser, P., Chilvers, C., Beral, V. and Hill, M.J. Nitrate and human cancer: a review of evidence. Int. J. Epidemiol. 9, (1980) 3-11.

[13] Gridley, G., McLaughlin, J.K., Block, G., Blot, W.J., Winn, D.M., Greenberg, R.S., Schoenberg, J.B., Preston-Martin, S., Austin, D.F. and Fraumeni, J.F., Jr. Diet and oral and pharyngeal cancer among blacks. Nutr. Cancer 14, (1990) 219-225.

[14] Hartman, P.E. Nitrate/nitrite ingestion and gastric cancer mortality. Environ. Mutagen. 5, (1983) 111-121.

[15] Ibrahim, A.S. Site distribution of cancer in Egypt: twelve years experience (1970-1981). In: Khogali, M., Omar, Y.T., Gjorgov, A., Ismail, 
A.S. (Eds) Cancer Prevention in Developing Countries. Oxford, Pergamon Press, (1986) 4550.

[16] Jones, R.W. and Garland, P.B. Sites and specificity of the reaction of bipyridylium compounds with anaerobic respiratory enzymes of Escherichia coli. Biochem. J. 164, (1977) 199211.

[17] Khairy, A.H., Badawi, A.F., El-Sokkary, I.H. and Mostafa, M.H. Concentration of nitrate and nitrite in vegetables, soil and water: a descriptive study in the Alexandria region, Egypt. In: ElRaey, M. (Ed.) Proceedings of the First Symposium of Environmental Sciences. Alexandria, Moharrem Bek Press, (1988) 155165.

[18] Krogh, P., Hald, B. and Holmstrup, P. Possible mycological etiology of oral mucosal cancer: catalytic potential of infecting Candida albicans and other yeasts in production of $\mathrm{N}$ nitrosobenzyl-methylamine. Carcinogenesis $\mathbf{8}$, (1987) 1543-1548.

[19] McLaughlin, J.K., Gridley, G., Block, G., Winn, D.M., Preston-Martin, S., Schoenberg, J.B., Greenberg, R.S., Stemhagen, A., Austin, D.F., Ershow, A.G. and Fraumeni, J.F., Jr. Dietary factors in oral and pharyngeal cancer. J. Natl. Cancer Inst. 80, (1988) 1237-1243.

[20] Mirvish, S.S. Role of $N$-nitroso compounds (NOC) and $N$-nitosation in etiology of gastric, esophageal, nasopharyngeal and bladder cancer and contribution to cancer of known exposures to NOC. Cancer Lett. 93, (1995) 17-48.

[21] Mostafa, M., Helmi, S., Badawi, A.F., Tricker, A., Spiegelhalder, B. and Preussmann, R. Nitrate, nitrite and volatile $N$-nitroso compounds in the urine of Schistosoma haematobium and Schistosoma mansoni infected patients. Carcinogenesis 15, (1994) 619-625.

[22] Murdia, U.S., Mehta, F.J. and Bhide, S.V. Nitrate reductase activity and nitrite levels in the saliva of habitual users of various tobacco products. Food Chem. Toxicol. 20, (1982) 269-271.

[23] Nair, J., Nair, U.J., Ohshima, H. and Bhide, S.V. and Bartsch, H. Endogenous nitrosation in the oral cavity of chewers while chewing betel acid with or without tobacco. IARC Sci. Publ. 84, (1987) 465-69.

[24] Rogers, M.A.M., Vaughan, T.L., Davis, S. and Thomas, D.B. Consumption of nitrate, nitrite, and nitrosodimethylamine and the risk of upper aerodigestive tract cancer. Cancer Epidemiol. Biomarkers Prev. 4, (1995) 29-36.

[25] Shapiro, K.B., Hotchkiss, J.H. and Roa, D.A. Quantitative relationship between oral nitratereducing activity and the endogenous formation of $N$-nitrosamino acids in humans. Food Chem. Toxicol. 29, (1991) 751-755.

[26] Spiegelhalder, B., Eisenbrand, G. and Preussmann, R. Influence of dietary nitrate and nitrite content of human saliva: possible relevance to in vivo formation of $\mathrm{N}$-nitroso compounds. Food Cosmet. Toxicol. 14, (1976) 545-548.

[27] Stephany, R.W. and Schuller, P.L. The intake of nitrate, nitrite and volatile $\mathrm{N}$-nitrosamines and the occurrence of volatile $N$-nitrosamines in human urine and veal calves. IARC Sci. Publ. 19, (1978) 443-460.

[28] Tannenbaum, S.R., Weisman, M. and Fett, D. The effect of nitrate intake on nitrite formation in human saliva. Food Cosmet. Toxicol. 14, (1976) 549-552.

[29] Tenovuo, J. The biochemistry of nitrates, nitrites, nitrosamines and other potential carcinogens in human saliva. J. Oral. Pathol. 15, (1986) 303307.

[30] Tricker, A.R., Mostafa, M.H., Spiegelhalder, B. and Preussmann, R. Urinary excretion of nitrate, nitrite and $N$-nitroso compounds in schistosomiasis and bilharzia bladder cancer patients. Carcinogenesis 10, (1989) 547-552.

[31] Tricker, A.R., Pfundstein, B., Kälble, T. and Preussmann, R. Secondary amine precursors to nitrosamines in human saliva, gastric juice, blood, urine and faeces. Carcinogenesis 13, (1992) 563-568.

[32] Vavilova, T.P. and Petrovich, A. Determination of nitrate reductase activity in mixed saliva. $J$. Med. Chem. 37, (1991) 69-72.

[33] Wettig, K., Uhlig, D., Broschinski L., Diener, W., Fischer, G. and Namaschk, A. Nitrate and nitrite in the urine, saliva and blood of urologic patients. J. Urol. Nephrol. 82, (1989) 667-670.

[34] Yang, C.S. and Wang, Z. Tea and cancer. J. Natl. Cancer Inst. 85, (1993) 1038-1049

[35] Ziebarth, D., Spiegelhader, B. and Bartsch, H. Nnitrosation of medicinal drugs catalyzed by bacteria from human saliva and gastro-intestinal tract, including Helicobacter pylori. Carcinogenesis 18, (1997) 383-389. 


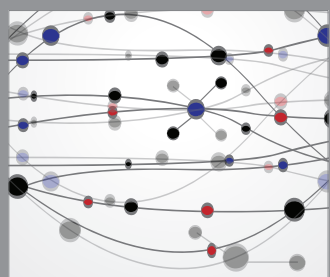

The Scientific World Journal
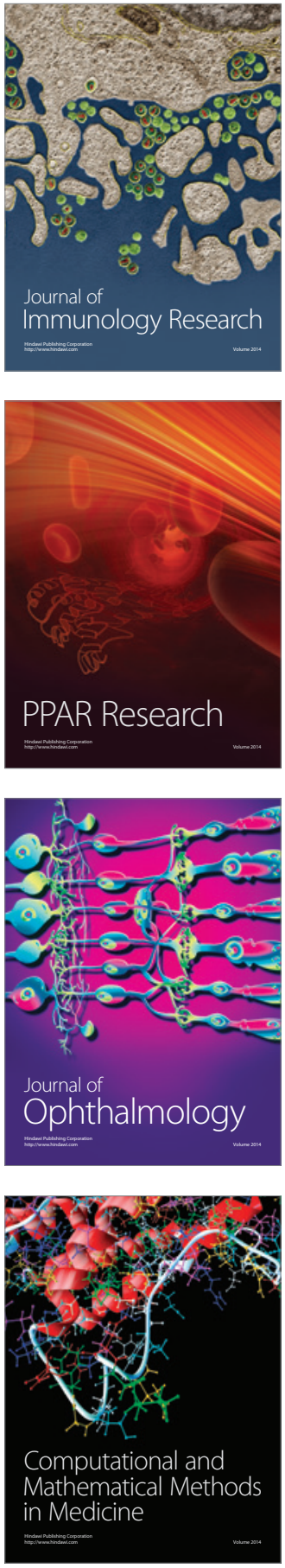

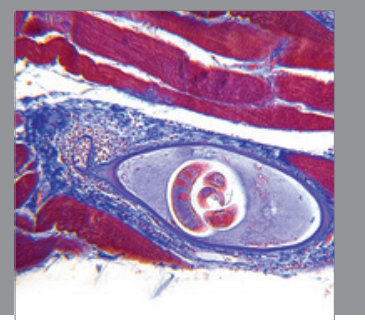

Gastroenterology

Research and Practice
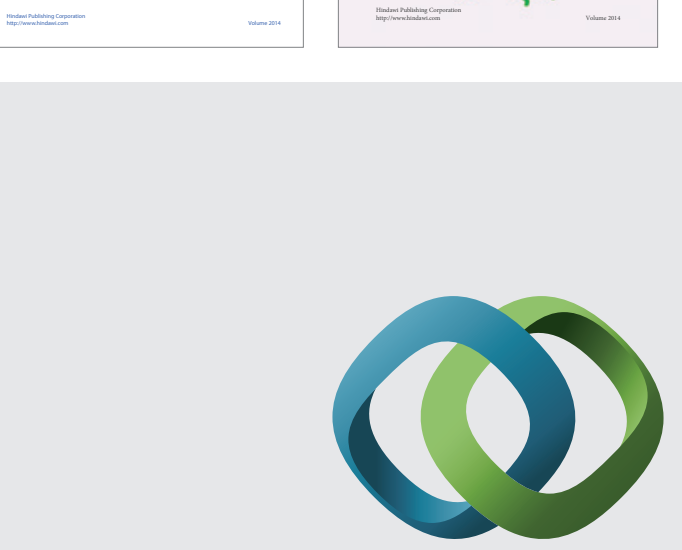

\section{Hindawi}

Submit your manuscripts at

http://www.hindawi.com
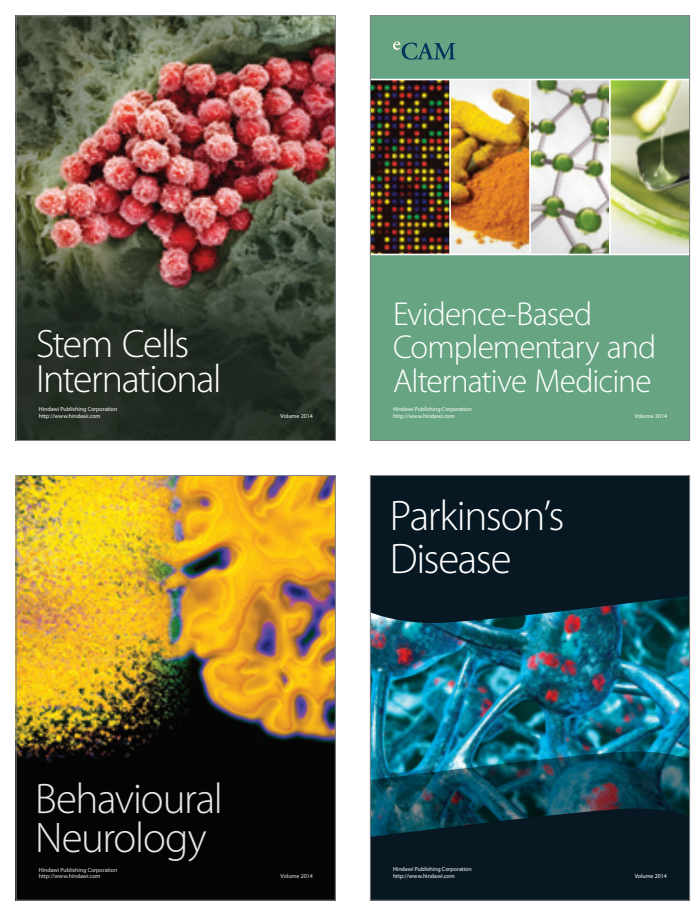

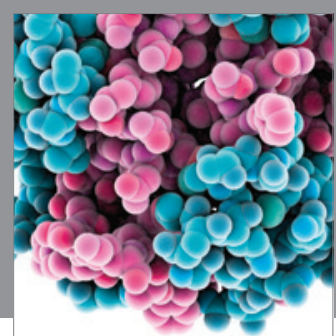

Journal of
Diabetes Research

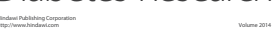

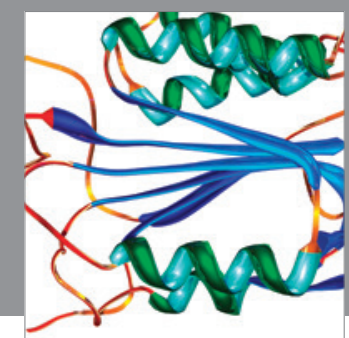

Disease Markers
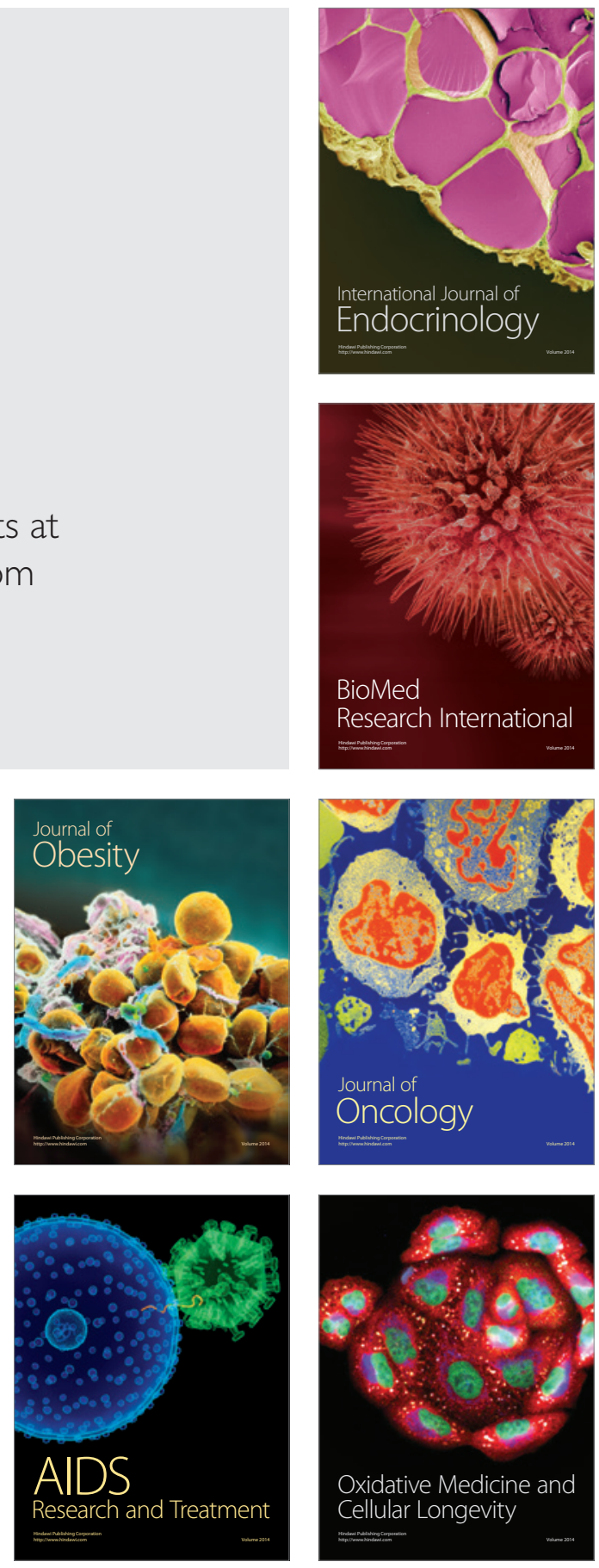